Recepción: 20 / 03 / 2018

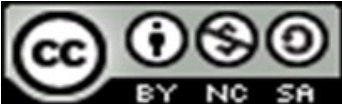

Aceptación: 19 / 05 / 2018

Ciencias económicas y empresariales

Publicación: 05 / 06 / 2018

Artículo de Investigación

\title{
Análisis del ámbito del código de ética en la contraloría social del Ecuador
}

Analysis of the scope of the code of ethics in the social comptroller of Ecuador Análise do alcance do código de ética da contraloria social do Equador

Edwin Reyes-Sarria ${ }^{\mathrm{I}}$ edwinreyessarria@hotmail.com

Daniel A. Miranda-Ledesma II danielmiranda@hotmail.com

Mauricio S. Quiroga-López ${ }^{\mathrm{III}}$ mauricioquiroga@hotmail.com

\section{Correspondencia: edwinreyessarria@hotmail.com}

\footnotetext{
I Docente de la Universidad Técnica “Luis Vargas Torres” de Esmeralda, Esmeralda, Ecuador.

${ }^{\text {II } M a g i s t e r ~ e n ~ D i r e c c i o ́ n ~ d e ~ E m p r e s a s, ~ C o n t a d o r ~ P u ́ b l i c o ~ a u t o r i z a d o, ~ E c o n o m i s t a ~ c o n ~ m e n c i o ́ n ~ e n ~ g e s t i o ́ n ~ E m p r e s a r i a l ~}$ especialización en Finanzas, Docente de la Universidad Laica “Eloy Alfaro” de Manabí, Manta, Ecuador.

${ }^{\text {III }}$ Magister en gerencia empresarial (MBA) mención gestión de proyectos, Abogado, Ingeniero industrial, Docente de la Universidad Técnica de Ambato, Ambato; Ecuador.
} 


\section{Resumen}

La contraloría social es un mecanismo innovador de participación ciudadana, orientado fundamentalmente al control y vigilancia de las acciones de gobierno por parte de quienes finalmente resultarán ser los beneficiarios de las mismas. El presente artículo propone un análisis del ámbito del código de ética en la contraloría social desde la perspectiva ecuatoriana. La metodología utilizada fue de tipo documental, permitiendo obtener y compilar información de interés para su posterior análisis, igualmente se hizo uso de la observación participante y la entrevista para documentar aspectos teóricos propios de la contraloría social en el ecuador. Entre los resultados se pudo evidenciar él esfuerzo de la contraloría social por garantizar la buena inversión de los recursos a través de la permanente supervisión y vigilancia de los mismos. Del mismo se pudo concluir, que las acciones de contraloría social que en la actualidad se llevan a cabo permiten ejecutar de forma eficiente los recursos públicos.

Palabras clave: contraloría social; código ético; participación ciudadana y perspectiva ecuatoriana.

\section{Abstract}

The social Comptroller is an innovator of citizen participation, mainly aimed at the control and monitoring of the actions of Government by those who finally will be beneficiaries of the same. This article proposes an analysis of the scope of the code of ethics in the social Comptroller from the Ecuadorian perspective. The methodology used was documentary-type, allowing to obtain and compile information of interest for further analysis, also made use of participant observation and interview for documenting theoretical aspects of the social Comptroller in Ecuador. Among the results he demonstrates effort of the social monitoring to ensure the good investment of resources through the permanent monitoring and surveillance of them. It could be concluded, the actions of social monitoring, which currently are held to allow run efficiently public resources.

Keywords: social accounting; code of ethics; participation citizen and Ecuadorian perspective. 


\section{Resumo}

O controlador social é um mecanismo inovador de participação cidadã, orientado fundamentalmente para o controle e a fiscalização das ações do governo por aqueles que acabarão por se tornar os beneficiários deles. Este artigo propõe uma análise do escopo do código de ética no controlador social a partir da perspectiva equatoriana. A metodologia utilizada foi do tipo documental, permitindo obter e compilar informações de interesse para sua posterior análise, também fez uso da observação participante e da entrevista para documentar aspectos teóricos do controlador social no equador. Entre os resultados foi possível demonstrar o esforço do controlador social para garantir o bom investimento dos recursos através da supervisão permanente e vigilância dos mesmos. Do mesmo modo, pode-se concluir que as ações de controle social atualmente realizadas permitem a execução eficiente dos recursos públicos.

Palavras chave: controlador social; código de ética; participação cidadã e perspectiva equatoriana.

\section{Introducción}

La contraloría social constituye una práctica de transparencia y de rendición de cuentas, que permite que los beneficiarios de las acciones de gobierno, de manera organizada, vigilen que los proyectos, servicios y obras, sean proporcionados con eficiencia, honestidad, oportunidad y calidad. Cabe destacar, que es una forma de empoderamiento de las comunidades, a partir de la participación ciudadana en aportar proyectos de solución a sus comunidades.

Al respecto, cabe señalar lo expuesto por Bayón (1998), quien la explica como una intervención de todos los ciudadanos tanto hombres como mujeres en las actividades de vigilancia, supervisión y control de los recursos que se aplican para desarrollar los planes, programas y proyectos que realiza cualquier dependencia gubernamental. Es de enfatizar que desde la contraloría social ese examina la legalidad y la corrección de los gastos públicos, por parte de las comunidades. En el caso particular del Ecuador, se teje el eslogan

"Todos somos parte del control”, lo cual es una campaña impulsada por la Contraloría General del Estado, que busca involucrar a los ciudadanos en la fiscalización de los asuntos de interés público. A tal efecto, Ceja (2012), expone que la contraloría social es una función compartida 
entre el Poder Público y los ciudadanos en pro de garantizar el manejo transparente y eficiente de los recursos públicos, en beneficio de los intereses de la sociedad. Por su parte Sartori (1998) la considera como el proceso en el que intervienen dos tipos de actores o sujetos: sujeto activo y sujeto pasivo. Se considera como sujeto activo a la sociedad o grupo dentro de ella que ejerce la presión o el control y como sujeto pasivo el individuo o grupo que recibe la presión para que adapte su conducta según los valores sociales.

Es de resaltar, que la posición planteada desde el organismo de control del Ecuador, fomenta la participación ciudadana y el control social, siguiendo los principios redactados en la carta magna. La Constitución de la República, en el artículo 204, establece que "el pueblo es el mandante y primer fiscalizador del poder público, en ejercicio de su derecho a la participación". Además, el artículo 95 insta a la ciudadanía a "participar de manera protagónica en el control popular de las instituciones del Estado y sus representantes, en un proceso permanente de construcción del poder ciudadano. La participación de la ciudadanía en todos los asuntos de interés público es un derecho, que se ejercerá a través de los mecanismos de la democracia representativa, directa y comunitaria". Bajo estos preceptos, "Todos somos parte del control" es un mecanismo institucional que invita a los ciudadanos, organizaciones sociales y actores políticos a presentar denuncias sustentadas, entregar información sobre posibles casos de mala utilización de recursos públicos o aportar con datos a las acciones de control que se encuentran en ejecución.

Esta información es sustancial para mejorar la administración de los recursos públicos. Si bien es cierto, la Contraloría tiene facultades para sancionar a los funcionarios por los actos u omisiones cometidos en el ejercicio de sus funciones, el objetivo del organismo de control es perfeccionar el sistema administrativo estatal, de manera que los ingresos que recibe el erario se utilicen bajo los principios de economía y eficiencia, tal como lo determina nuestra Constitución. A partir de esta posición, el presente estudio pretende propone un análisis de la contraloría social desde la perspectiva latinoamericana, de forma específicamente el caso de Ecuador.

\section{Desarrollo}

La Contraloría Social. La Contraloría Social, según Venezuela (2005) es vista como la nueva forma de relación entre el Estado y los ciudadanos, orientada al rescate del principio de responsabilidad y corresponsabilidad entre la actividad gubernamental y la participación 
ciudadana, por tanto, toma carácter de derecho y deber dentro del tratado constitucional, en el cual se establece claramente su definición. Desde la perspectiva que marca esta consideración, se puede afirmar que la Contraloría Social es la participación de todos los ciudadanos en las actividades de vigilancia, supervisión y control de los recursos que se aplican para desarrollar los planes, programas y proyectos que las instancias gubernamentales realizan. En este sentido, la Contraloría Social es el derecho de todos los ciudadanos de intervenir en la vigilancia, seguimiento y monitoreo de la gestión pública, con la finalidad de que se verifiquen los principios de transparencia, eficacia, eficiencia, efectividad, honestidad, rendición de cuentas, seriedad, cumplimiento y calidad que deben regir, para evitar la corrupción, en la que ha de evitar la utilización de los recursos públicos para fines diferentes a la ejecución de proyectos de tipo social.

\section{Acciones a cumplir por la contraloría social. Es responsabilidad desde las comunidades:}

Velar para que los recursos que se asignen a una comunidad para una determinada obra no sean desviados para otros fines; que los materiales que se compren sean los más baratos, pero con la calidad requerida; que la obra se ejecute hasta el final y no quede a medio camino.

La contraloría social permite dar seguimiento a las actividades administrativas y de funcionamiento ordinario del consejo comunal en su conjunto.

Es el medio para ejercer el control, fiscalización y vigilancia de la ejecución del plan de desarrollo comunitario.

Permite prevenir a tiempo irregularidades, desviaciones de los recursos destinados a obras, servicios, programas y proyectos sugiriendo cómo corregirlas.

Contribuye al cumplimiento de las leyes y procedimientos en la ejecución de las obras, servicios, programas y proyectos financiados con fondos públicos.

Incentiva la confianza ciudadana en la incorporación social a la vigilancia sobre los recursos destinados a satisfacer las necesidades de la colectividad.

\section{Contraloría social en Ecuador}

La Contraloría social en el Ecuador, está siendo considerado de gran interés y transcendencia social por parte de sus ciudadanos, al estar a la mano para todos sin ningún tipo de distinción ideológica o partidista. En términos generales, la contraloría social constituye un derecho y también un deber garantizado por la Constitución y sus legislaciones. En el caso de las 
comunidades ecuatorianas, el cual posee una unidad de contraloría social, que tiene el deber de detectar problemas en la comunidad y realizar las denuncias correspondientes.

\section{La contraloría general del estado y la ciudadanía}

La identidad institucional y misión de la Contraloría General del Estado, radica en el control de la utilización de los recursos estatales, y la consecución de los objetivos de las instituciones del Estado y de las personas jurídicas de derecho privado que dispongan de recursos públicos. Realiza un trabajo fundamentado en la ética, transparencia, calidad y enfoque hacia los resultados, que garanticen a la ciudadanía el eficiente control de los recursos públicos. La Contraloría General del Estado, dentro del marco de respeto irrestricto de los Derechos Humanos, debe observar los siguientes parámetros de atención a los intereses de la ciudadanía: 1. Protección de datos de los usuarios. La Contraloría General del Estado se compromete a velar por el buen uso de los datos personales de los sujetos de control y de sus servidores y a guardar la privacidad de los mismos, utilizándolos solo para los fines institucionales previstos. 2. Promoción de la igualdad de género. Mujeres y hombres tienen las mismas facilidades de acceso, representación e intervención en los procesos de participación, rendición de cuentas y oportunidades dentro de la Contraloría General del Estado. En todos los casos se tiene que procurar un equilibrio de género en cuanto al número de los integrantes de los diferentes estamentos organizativos y jerárquicos. (Constitución de la Republica de Ecuador, 2008).

\section{La contraloría general del estado y los sujetos de control}

La constitución de la república del Ecuador, contempla que los sujetos de control merecen, por parte de la Contraloría General del Estado, la atención, asesoría e información profesional, referente al cumplimiento de sus responsabilidades mutuas. Las servidoras y servidores de la Contraloría General del Estado, procederán de manera veraz y oportuna. Asimismo, la Contraloría General del Estado receptará y tramitará de modo ágil las denuncias por actos de corrupción en el uso de los recursos públicos, ya sea de los sujetos de control como de sus servidoras y servidores. En toda denuncia debidamente fundamentada se observará el cumplimiento del debido proceso y la presunción de inocencia.

\section{Gestión del código de ética para la contraloría del estado ecuatoriano}

El Código de Ética debe ser acatado por todas las servidoras y servidores de la Contraloría General del Estado, como un compromiso ético y moral, y su estudio formará parte de la inducción a todo el personal de la entidad. 
El Código de Ética se publicará y entregará a toda servidora y servidor de la Contraloría General del Estado, estará disponible para todo sujeto de control y público en general en los canales institucionales de comunicación y distribución de impresos.

El Código de Ética se publicará en un lugar preferente de la página web institucional, de libre acceso para toda la ciudadanía.

La Dirección de Asuntos Éticos y Participación Ciudadana es la responsable de la gestión, comunicación, distribución, publicación, inducción y revisión del Código de Ética, en coordinación con las instancias institucionales pertinentes.

La Dirección de Asuntos Éticos y Participación Ciudadana organizará comités de ética regionales, instancias que se encargarán de las actividades que involucren al Código de Ética.

Los comités de ética regionales aportarán con asesoría ética en las instancias institucionales, personales y en los casos en que sean requeridos.

Los comités de ética regionales estarán dirigidos por servidoras o servidores de asuntos éticos, que certifiquen la preparación profesional correspondiente en conocimiento y manejo de asuntos éticos.

Los comités de ética regionales motivarán y estimularán la conducta ética ejemplar de las servidoras y servidores de la Contraloría General del Estado.

La Dirección de Asuntos Éticos y Participación Ciudadana conjuntamente con los comités de ética regionales evaluarán el conocimiento, aplicación e incidencia institucional del Código de Ética de la

El ámbito del código de ética, abarca los mismos códigos que rigen otras organizaciones profesionales, entendiendo que las infracciones y el quebrantamiento de sus normas originarán las responsabilidades correspondientes. Las denuncias de actos en contra de la ética pública, debidamente fundamentadas, serán procesadas por la Dirección de Talento Humano y las instancias institucionales pertinentes, observando los principios de protección y reserva del denunciante; así como, los del debido proceso y presunción de inocencia del denunciado. (Código de ética de la contraloría general del Estado, 2012).

\section{Metodología}

La metodología asumida en el presente artículo se centró en una investigación documental bibliográfica, realizado mediante el método hermenéutico, que permitió la interpretación de los 
contenidos cuya finalidad fue construir contextos conceptuales que conllevaron al análisis desde el ámbito del código de ética en la contraloría social del ecuador y cuyo orientación interpretativa definido por Sandín (2003) lo explica como aquel que "desarrolla interpretaciones de la vida social y el mundo desde una perspectiva cultural e histórica" (pag.53). El corpus del estudio estuvo constituido por los estamentos legales que rigen en materia de contraloría social en el ecuador.

\section{Análisis documental}

La Constitución de la República del Ecuador en los artículos 3 numeral 4, la responsabilidad ética del ejercicio de las funciones de las ecuatorianas y ecuatorianos, todo ello para evitar sanciones que empañen su labor profesional, regido mediante el Acuerdo 034-CG del 24 de octubre del 2002, publicado en el Registro Oficial 697 de 5 de noviembre del 2002, de los Servidores de la Contraloría General.

Los valores corporativos en una organización, en los servidores de la contraloría, deben ser los que inspiren y orienten la totalidad de sus acciones, y así lograr promover y alentar a quienes hacen la institución a asumirlo con entusiasmo.

Los principios éticos constitucionales de inclusión o no discriminación, de igualdad de todas las personas, de equidad, de respeto y de rendición de cuentas a la ciudadanía deben orientar el quehacer de la contraloría social en el cumplimiento de sus funciones y alentar el accionar de todas sus servidoras y servidores.

Los principios éticos de la contraloría general del Estado de Control, prevención y lucha contra la corrupción, legalidad, beneficio social, imparcialidad y autonomía han de direccionar a la Contraloría General del Estado, fundamentándose en el más irrestricto respeto a la ley, a su mandato constitucional, y a su misión, visión y experiencia histórica.

Los valores de integridad, transparencia., responsabilidad y lealtad de las servidoras y servidores de la Contraloría general del Estado han de estar en consonancia con el Mandato Constitucional y la misión y visión institucional, para así crear un clima laboral beneficioso para todos y usar las instancias institucionales para resolver los conflictos en el ámbito laboral argumentados en la honestidad y buena fe de las personas, sin prejuicio por diversidad étnica, ideología, o clase social. 
Se espera de la Contraloría General del Estado y sus proveedores un comportamiento ético, en la que asume cero tolerancias a las prácticas ajenas al Código de Ética, y priorizará la contratación de productos y servicios amigables con el medioambiente y provenientes de proveedores locales y mantener relaciones cordiales y de coordinación con las otras instancias del Estado, sin comprometer su competencia, autonomía, responsabilidad, funciones, alcances, recursos y rendición de cuentas a la ciudadanía.

En cuanto a la Contraloría general del estado y los organismos internacionales, han de cumplirse los compromisos internacionales adquiridos de acuerdo con la Constitución y la ley, y de esta forma mantener una imagen de responsabilidad y buena reputación a nivel internacional.

Fue posible develar desde la normativa que rige la Contraloría general del estado el respeto del derecho que tiene toda persona en forma individual o colectiva a una comunicación libre, intercultural, incluyente, diversa y participativa, dentro del marco legal vigente y la disposición de todos los canales institucionales para un libre acceso de la ciudadanía y los medios de comunicación, para solicitar la información que se genere como entidad pública.

\section{Conclusiones}

La contraloría social se constituye en un medio que permite la participación de los ciudadanos en la comunidad en pro de hacer seguimiento y vigilar los recursos asignados para la ejecución de un bien social, dando apertura a su intervención en los asuntos públicos y resolver los problemas que afectan su entorno. Además, la comunidad puede vigilar los recursos que son ejecutados para la resolución de problemas o puesta en marcha de distintos proyectos, verificando que son utilizados de manera eficiente.

Se pudo constatar en el análisis de los documentos que es de interés tanto de la comunidad como de las autoridades que llevan a cabo la ejecución de obras de interés social en las comunidades que se lleve a feliz término lo ejecutado y de esta manera evitar las sanciones éticas previstas en la constitución.

A partir de la contraloría social es posible denunciar los desvíos en la utilización de los recursos públicos, los cuales remite la información para que la Contraloría General del Estado inicie las acciones pertinentes. Esta información es sustancial para mejorar la administración de los 
recursos públicos, al ejercer sus facultades para sancionar a los funcionarios por los actos $\mathrm{u}$ omisiones cometidos en el ejercicio de sus funciones.

\section{Referencias Bibliográficas}

Álvarez, A. (2008) "Manual de normas y procedimientos para la contraloría social en el marco de la ley de los consejos comunales". Consultado el 12 de diciembre de 2014. Disponible en: http://goo.gl/X2wKHJ

Bayón, M. C., Roberts, Bryan y G. Saraví (1998), "Ciudadanía social y sector informal en América Latina", en Perfiles Latinoamericanos, año 7, núm. 13, diciembre, 1998. México: Facultad Latinoamericana de Ciencias Sociales, pp. 73-111.

Cejas (2012). Contraloría Social. Disponible en: indd - iapem iapem.mx/.../2012\%20152\%20El\%20papel\%20de\%201a\%20contraloria\%20social.pd

CODIGO DE ETICA DE LA CONTRALORIA GENERAL DEL ESTADO (2012). Acuerdo de la Contraloría General del Estado 6 Registro Oficial 652 de 02-mar.-2012 Estado: Vigente. CONSTITUCION DE LA REPUBLICA DEL ECUADOR (2008). Decreto Legislativo 0 Registro Oficial 449 de 20-oct-2008 Ultima modificación: 13-jul-2011 Estado: Vigente.

Sartori, G. (1998) "El discurso liberal: democracia y representación", en Rafael del Águila y Fernando Vallespín (coordinadores), La democracia en sus textos. Madrid: Alianza.

Venezuela, M. (2005). "El control social”. Editorial del Boletín SABER COMO. Instituto de Tecnología industrial. INTI. Argentina. 